\title{
Sistem Informasi Penjualan Makanan Dan Minuman Di Wejie Kopi Berbasis Web
}

\author{
Rismaniah ${ }^{1}$, Kudiantoro Widianto ${ }^{2, *}$, Tyas Setiyorini $^{3}$ \\ ${ }^{1}$ Sistem Informasi; STMIK Nusa Mandiri Jakarta; Jalan Jatiwaringin No. 2, Cipinang Melayu, \\ Makasar Jakarta Timur. (021) 8005722; e-mail: rsmniah15@gmail.com \\ 2 Teknologi Informasi; Universitas Bina Sarana Informatika; Jl. Kramat Raya No. 98 Jakarta \\ (021) 8000063; e-mail: kudiantoro.kdw@bsi.ac.id \\ ${ }^{3}$ Teknik Informatika; STMIK Nusa Mandiri Jakarta; Jalan Jatiwaringin No. 2, Cipinang Melayu, \\ Makasar Jakarta Timur. (021) 8005722; e-mail: tyas.tys@nusamandiri.ac.id \\ * Korespondensi: e-mail: kudiantoro.kdw@bsi.ac.id
}

Diterima: 08 Desember 2020 ; Review: 20 Desember 2020 ; Disetujui: 26 Desember 2020

Cara sitasi: Rismaniah, Widianto K, Setiyorini T. 2020. Sistem Informasi Penjualan Makanan Dan Minuman Di Wejie Kopi Berbasis Web. Information Management for Educators and Professionals. 5(1): 55-66.

Abstrak: Wejie Kopi adalah sebuah usaha di bidang kuliner yang terletak di Kalisari, Jakarta Timur tempat bersantai yang cocok untuk kalangan anak muda. Sistem order secara manual pada suatu restoran atau kafe dapat menimbulkan beberapa masalah. Masalah pada Wejie Kopi yakni sering terjadinya customer menunggu terlalu lama umtuk mendapatkan menu pemesanan karena harus menunggu pelayan memberikan menu pemesanan. Maka didalam menyelesaikan masalah tersebut diusulkan dalam merancang sebuah sistem dimana dalam pemesanan menu dilakukan oleh customer menggunakan web dimaksudkan agar customer dapat langsung melihat menu pada sebuah restoran. Dalam perancangan web menggunakan Metode Waterfall dan menggunakan pemrograman PHP serta format database MySql. Dengan perancangan sistem ini diharapkan perusahaan akan memperoleh beberapa kemudahan dalam proses transaksi yang ada di Wejie Kopi.

Kata kunci: penjualan makanan dan minuman, PHP, mysql, waterfall

Abstract: Abstract: Wejie Kopi is a culinary business located in Kalisari, East Jakarta, a place to relax which is suitable for young people. The manual ordering system for a restaurant or cafe can cause some problems. The problem with Wejie Kopi is that customers often wait too long to get an order menu because they have to wait for the waiter to give the order menu. So in solving this problem it is proposed to design a system where the menu ordering is done by the customer using the web so that the customer can immediately see the menu at a restaurant. In web design using the Waterfall method and using PHP programming and MySql database format. By designing this system, it is hoped that the company will find several facilities in the transaction process at Wejie Kopi.

Keywords: food and beverage sales, PHP, mysql, waterfall.

\section{Pendahuluan}

Perkembangan teknologi informasi belakangan ini sangat cepat, teknologi hampir berkesinambungan dengan setiap kegiatan manusia. Umumnya manusia mempergunakan teknologi untuk kebutuhan pribadi maupun untuk keperluan dalam peningkatan usahanya. Teknologi kini tidak hanya perusahaan dan organisasi besar yang memanfaatkannya. Pemanfaatan teknologi juga mulai merambah ke bidang usaha kuliner seperti restoran dan rumah makan [1]. Berdasarkan data dari Kementrian Pariwisata dan Ekonomi Kreatif (KEMENPAR) jumlah usaha dibidang tersebut terus mengalami peningkatan khususnya dibidang restoran. Perkembangan usaha tersebut mencapai angka 200 pertahunnya dengan rata-rata tenaga kerja yang diangkat adalah 27 orang tiap usaha [2]. Wejie Kopi adalah sebuah usaha di bidang kuliner yang terletak di Kalisari, Jakarta Timur tempat bersantai yang cocok 
untuk kalangan anak muda. Saat ini proses pemesanan menu di Wejie Kopi masih menggunakan cara manual sehingga menghabiskan banyak waktu dan tenaga. Sistem order secara manual pada suatu restoran atau kafe dapat menimbulkan beberapa masalah[3]. Permasalahan yang ada pada Wejie Kopi yakni sering terjadinya customer menunggu terlalu lama umtuk mendapatkan menu pemesanan karena harus menunggu pelayan memberikan menu pemesanan. Masalah yang kedua adalah sering terjadinya kekeliruan dalam pesanan dan kesulitan memilih pesanan yang harus di olah terlebih dahulu. Masalah yang ketiga adalah sering terjadinya salah komunikasi antara pelayan dan koki karena catatan yang hanya tertulis tangan dan terkadang kerap terjadi hilangnya bukti pesenan pembeli. Masalah selanjutnya adalah sangat sering terjadi antrian yang panjang dalam menunggu pembayaran yang masih menggunakan sistem manual dan akan membuat kesulitan meningkat.

Dengan masalah yang sedang dihadapi oleh Wejie Kopi maka kehadiran website sangat dibutuhkan. Pemesanan menu dilakukan oleh customer menggunakan web dimaksudkan agar customer dapat langsung melihat menu pada sebuah restoran [4]. Website ini diharapkan bisa membantu permasalahan yang tengah dihadapi oleh Wejie Kopi agar dapat memperbaiki kualitas kafe.

\section{Metode Penelitian}

Metode Penelitian yang digunakan dalam perancangan website Wejie Kopi adalah:

\subsection{Teknik Pengumpulan Data}

Dalam pengumpul data menggunakan cara: 1. Observasi: mengumpulkan sebuah informasi dan pengamatan langsung yang berhubungan dengan masalah sistem pemesanan pada Wejie Kopi; 2. Wawancara: melakukan metode tanya jawab mengenai semua yang berhubungan dengan proses penjualan dengan pemilik Wejie Kopi yaitu Bapak Hartanto; 3. Studi Pustaka: dalam metode studi pustaka (literature), seperti buku-buku, jurna-jurnal, dan media internet yang mengenai pembuatam website. Dan bacaan lain yang sangat sesuai dengan penelitian ini.

\subsection{Metode Pengembangan Software}

Metode pengembangan software yang diterapkan pada perancangan website Wejie Kopi yaitu dengan menggunakan metode waterfall atau Sekuensial Linear atau alur hidup klasik (Classic Life Cycle) menyediakan pendekatan alur hidup perangkat lunak secara sekuensial atau terurut dimulai dari Analisis, Desain, Pengkodean, Pengujian dan Tahapan Pendukung (Support). Adapun tahapan-tahapan metode waterfall [5], sebagai berikut: 1. Analisa Kebutuhan software: Di Wejie Kopi khususnya masalah pada penjualan makanan dan minuman lalu mendefinisikan masalah tersebut. Kemudian mendeskripsikan sistem yang sudah berjalan di Wejie Cafe dan memberikan rekomendasi perbaikan, meningkatkan atau bahkan mengganti sistem yang sudah berjalan dengan pembuatan website ini. Sehingga software yang diterapkan bisa berjalan dengan efektif dan efesien. Software yang akan digunakan dalam perancangan web ini adalah PHPMyAdmin [6], XAMPP [7], Java Script, MySQL [8], dan Codelnteger [9]; 2. Desain: Membuat sebuah rancangan proses-proses dan kebutuhankebutuhan sistem yang berkaitan dengan pengembangan sebuah aplikasi ada pada tahap ini. Perangkat lunak dalam tahap ini digunakan untuk mendukung sistem meliputi desain sistem dengan menggunakan Unified Modeling Language [10], mendesain user interface, manajemen user, manajemen file, membuat rancangan input output dan membuat rancangan keamanan web dan menggunakan database Entity Relationship Diagram [11]; 3. Code Generation: Merupakan proses sebuah penerjemahan desain sistem yang telah dibuat kedalam perintahperintah yang nantinya akan dimengerti komputer dengan mempergunakan sebuah metode terstruktur; 4. Testing: Untuk memastikan sebuah sistem yang akan dibuat dan dapat digunakan dengan baik maka pada tahap ini dilakukan sebuah proses pengujian program dengan menggunakan black box testing [12]; 5. Support: Tahap ini adalah pemilihan sarana pendukung spesifikasi support software dan hardware sehingga akan membantu dalam perancangan web penjualan pada Wejie Kopi. Dalam membangun sebuah web sesuai pada sasaran sangat membutuhkan support software dan hardware yang memiliki peranan penting.

\section{Hasil dan Pembahasan}

\subsection{Analisa Kebutuhan Sistem}

Prosedur sistem pada Wejie Kopi untuk melakukan proses kegiatannya ada beberapa tahapan. Diawali dengan customer datang menduduki tempat yang telah disediakan kemudian 
meminta daftar menu pesanan, dan pramusaji datang untuk memberikan daftar menu pesanan beserta nota pesanannya. Customer dapat memilih menu pesanan dengan melihat daftar menu beserta daftar harganya yang diberikan oleh pramusaji, setelah selesai memilih menu pesanan, customer akan memberikan nota pesanannya kepada pramusaji. Dan pramusaji akan memberikan nota pesanan tersebut kepada bagian dapur untuk segera disiapkan menu pesanan customer. Setelah bagian dapur selesai meyiapkan pesanan sesuai dari nota pesanan yang diterimanya dari pramusaji, pramusaji mengantarkan pesanan tersebut ke customer sesuai dengan no meja yang sudah dicatat pada nota pesanan, Selanjutnya nota pesanan yang telah dibuat sebelumnya diberikan kepada kasir untuk bukti pesanan. Pada proses selanjutnya customer melakukan pembayaran kepada kasir dengan menyebutkan no meja posisi customer saat menikmati pesanannya kemudian kasir mencari dan mengecek nota pesanan yang sudah dibuat sebelumnya apakah sesuai dengan pesanan customer dan sebagai bukti pesanan. Setelah itu kasir memberikan struk pembayaran kepada customer.

Dari Prosedur yang ada bisa di buat analisa kebutuhan terdiri dari Customer: Customer dapat melihat daftar menu, customer dapat mengelola keranjang pesanan, customer dapat mengisi detail pemesan, dan customer dapat mengkonfirmas pesanan. Dan Kasir: Kasir dapat melakukan login, kasir dapat mengelola menu kategori, kasir dapat mengelola menu transaksi, kasir dapat melihat pesanan customer, kasir dapat mengkonfirmasi pembayaran, kasir dapat mengelola menu report, dan kasir dapat melakukan logout.

\subsection{Desain}

Entity Relationship Diagram (ERD): Tahapan dalam perancangan ERD sistem informasi penjualan makanan dan minuman di Wejie Kopi berbasis web yaitu: 1. Indentifikasi Entitas; 2. Menentukan Atribut Key; 3. Identifikasi Relasi; 4. Membuat Design Perkiraan; 5. Menentukan Kardinalitas. Berikut ini Gambar 1. Entitiy Relationship Diagram:

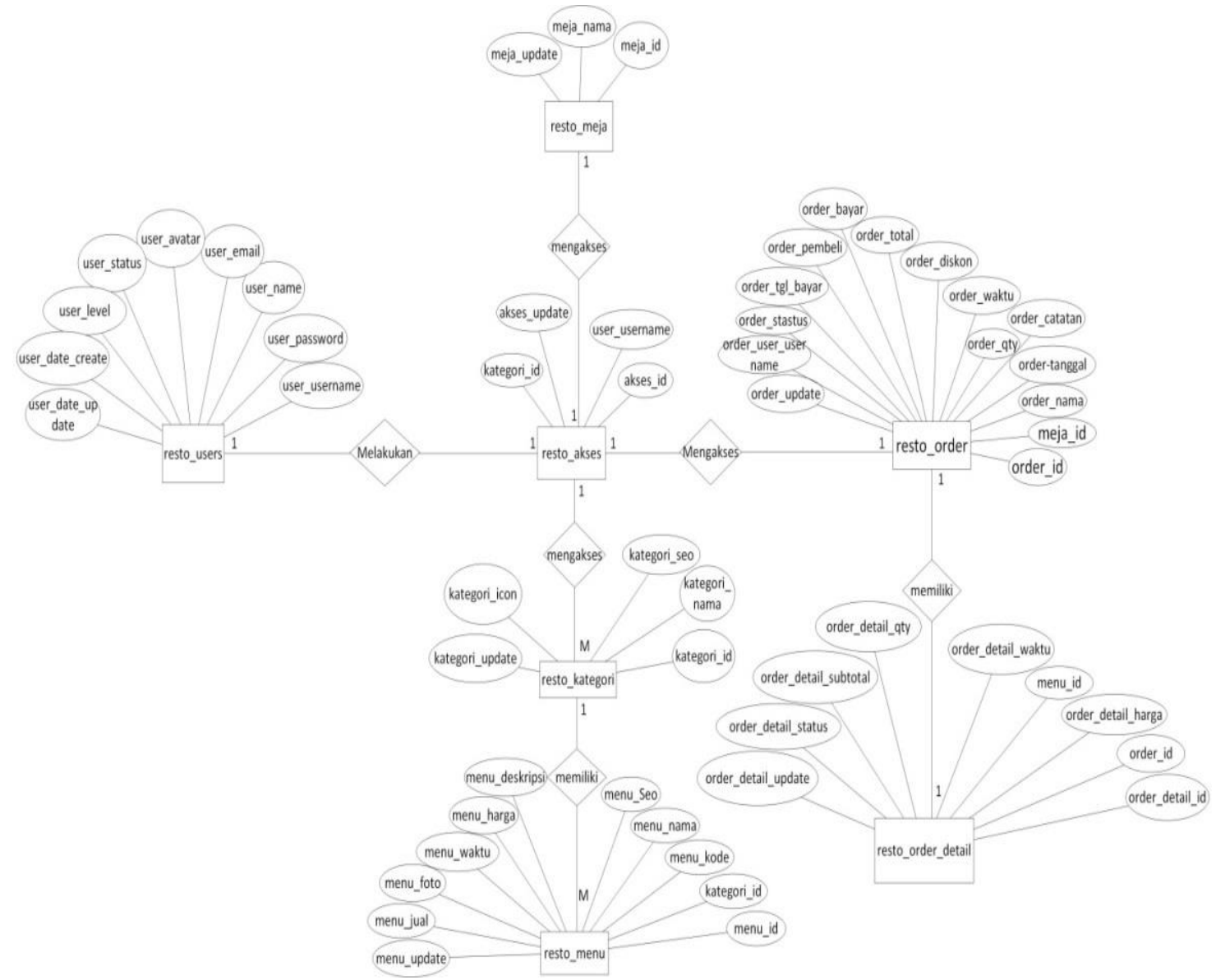

Sumber: Hasil Penelitian (2020)

Gambar 1. Entity Relationship Diagram (ERD) 
Logical Record Structure (LRS): Gambar 2. LRS sistem informasi penjualan makanan dan minuman di Wejie Kopi berbasis web adalah representasi dari struktur record-record pada tabel-tabel yang terbentuk dari hasil antar himpunan entitas.

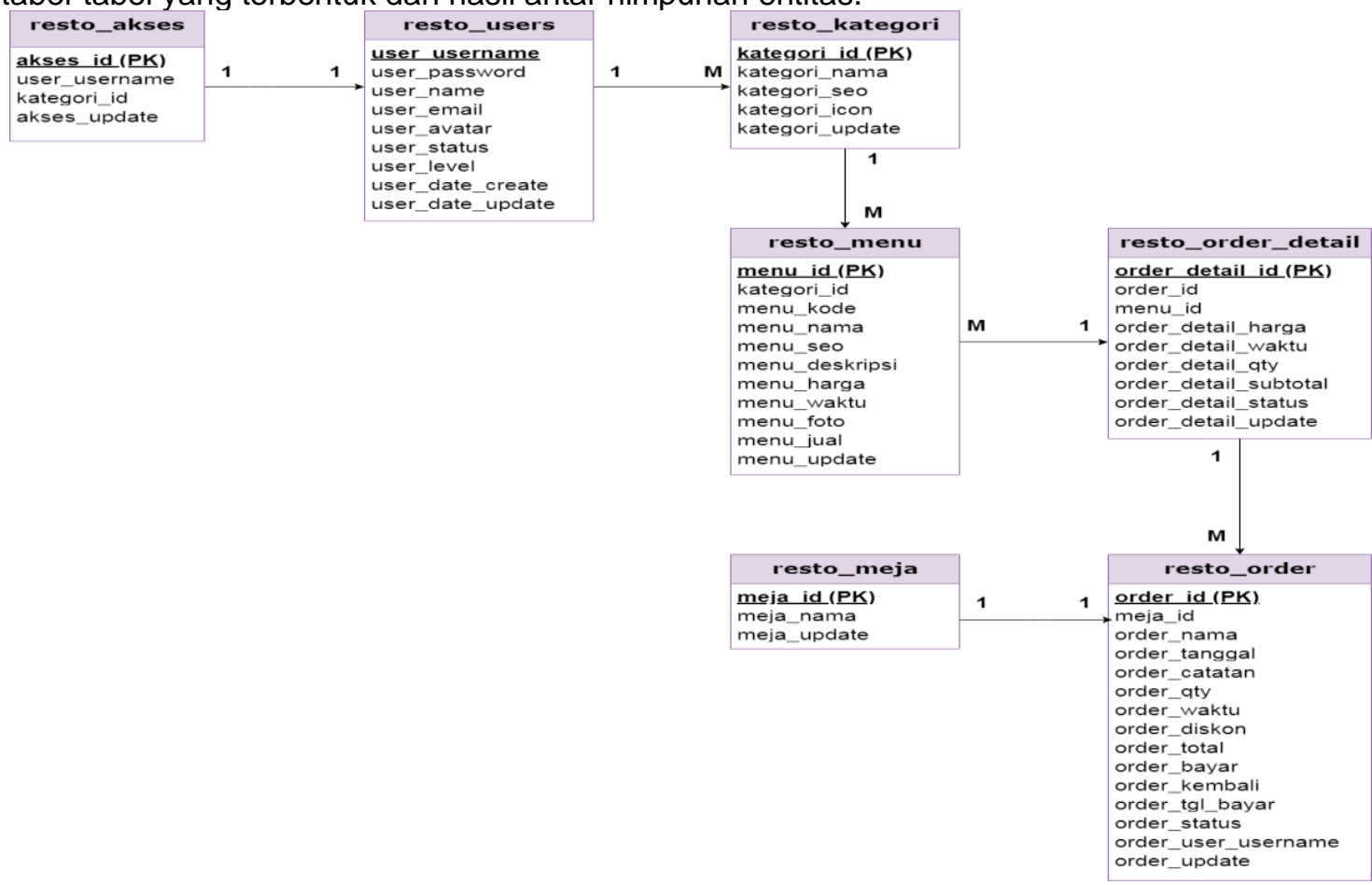

Sumber: Hasil Penelitian (2020)

Gambar 2. Logical Record Structure (LRS)

Tampilan Interface: Gambar 3. Tampilan Interface sistem informasi penjualan makanan dan minuman di Wejie Kopi berbasis web:

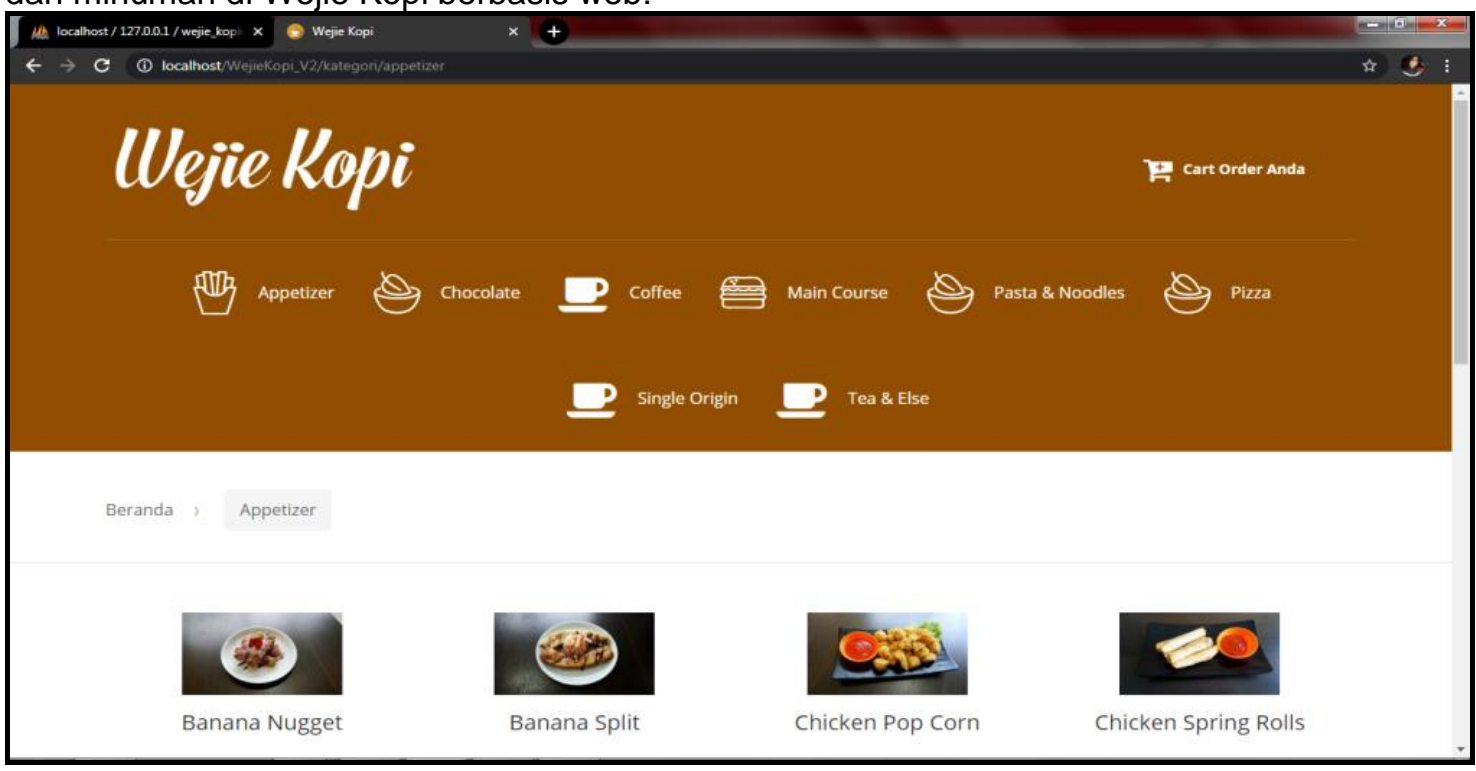

Sumber: Hasil Penelitian (2020)

Gambar 3. Tampilan Interface Halaman Daftar Menu pada Customer

\subsection{Code Generation}

Dalam merancang website untuk sistem informasi penjualan makanan dan minuman di Wejie Kopi berbasis web menggunakan beberapa bahasa penmrograman seperti PHP, Hypertext Markup Language (HTML), Javascript dan Cascading Style Sheet (CSS). 


\section{Admin Home.php}

d('BASEPATH') or exit('No direct script access allowed');

class Home extends MY_Controller

\{

public function _ construct()

\{ parent::_construct();

\$this->cek_auth_admin();

\$this->load->library('template');

\$this->load->model('admin/home_m'); \}

public function index()

$\{$ \$data['TotalMenu'] = \$this->db->get('resto_menu')->result();

\$data['TotalMonth'] = \$this->db->select_sum('order_total', 'total')-

$>$ get_where('resto_order', array('order_status' $=>2$, 'MONTH(order_tanggal)' $=>$

date('m'), 'YEAR(order_tanggal)' => date('Y')))->row();

\$data['Totallncome'] = \$this->db->select_sum('order_total', 'total')-

$>$ get_where('resto_order', array('order_status' $=>2$ )) $->\operatorname{row}($ );

\}

\$this->template->display('admin/home_v', \$data); \}

/* Location: appl./ication/controller/admin/Home.php */

\section{Admin Kategori.php}

$<$ ?php

defined('BASEPATH') or exit('No direct script access allowed');

class Kategori extends MY_Controller

\{ public function _ construct()

\{ parent::_construct();

\$this->cek_auth_admin();

\$this->load->library('template');

\$this->load->model('admin/kategori_m'); \}

public function index()

\{ \$this->template->display('admin/master/kategori_v') \}

public function data_list()

\{ $\quad$ \$List $=$ \$this->kategori_m->get_datatables ()$;$

$\$$ data $=$ array () ;

\$no = \$ POST['start'];

foreach (\$List as $\$ r$ ) \{

$\$$ no++;

\$row = array () ;

\$kategori_id = \$r->kategori id;

\$rowl] = '<a title="Edit Data" href="javascript:void(0)" onclick="edit_data(' . "'" . \$kategori_id. "'" . ')">

$$
<\text { i class="icon-pencil" }></ i>
$$

$$
</ a>
$$

$<$ a onclick="hapusData(' . \$kategori_id . ')" title="Delete Data"> $<$ i class="icon-close" $></ i>$

$$
</ a>\text {; }
$$

\$row []$=$ \$no;

\$row $]=\$ r->$ kategori nama;

\$row []$=\$ r->$ kategori_icon;

$\$$ data[] $=$ \$row

\$output = array (

"draw" => \$_POST['draw'],

"recordsTotal" $=>$ \$this->kategori_m->count_all(),

"recordsFiltered" => \$this->kategori_m->count_filtered(),

"data" $\quad=>$ \$data,

\}

); echo json_encode(\$output);

public function savedata() 


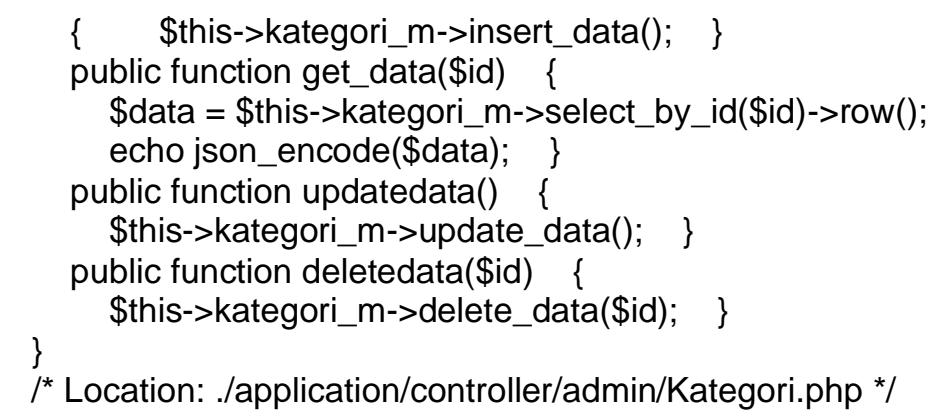

\section{Admin Lap_penjualan.php}

$<$ ?php

defined('BASEPATH') or exit('No direct script access allowed');

class Lap_penjualan extends MY_Controller

\{ public function _ construct()

\{ parent::_construct();

\$this->cek_auth_admin();

\$this->load->library('template');

\$this->load->model('admin/lap_penjualan_m'); \}

public function index()

\{ \$data['listData'] = \$this->db->get('resto_kategori')->result();

\$this->template->display('admin/report/lap_penjualan_v', \$data); \}

public function preview (\$dari = 'all', \$sampai = 'all', \$kategori = 'all')

\{ if (\$dari != 'all' \&\& \$sampai != 'all' \& \& \$kategori == 'all') \{

\$tgl_dari = date('Y-m-d', strtotime(\$dari));

\$tgl_sampai = date('Y-m-d', strtotime $(\$$ sampai) $)$;

\$data['listData'] = \$this->db->order_by('order_id', 'asc')-

$>$ get_where('v_order_detail', array('order_tanggal $>==^{\prime}=>$ \$tgl_dari, 'order_tanggal $<=$ '

$=>$ \$tgl_sampai))->result();

\} elseif (\$dari != 'all' \&\& \$sampai != 'all' \&\& \$kategori != 'all') \{

\$tgl_dari = date('Y-m-d', strtotime(\$dari));

\$tgl_sampai = date('Y-m-d', strtotime(\$sampai));

\$data['listData'] = \$this->db->order_by('order_id', 'asc')-

$>$ get_where('v_order_detail', array('order_tanggal $>==^{\prime}=>$ \$tgl_dari, 'order_tanggal $<=$ '

$=>$ \$tgl_sampai, 'kategori_id' => \$kategori))->result();

\} elseif ( $\$$ dari $==$ 'all' \& \& \$sampai $==$ 'all' \& \& \$kategori != 'all') \{

\$data['listData'] = \$this->db->order_by('order_id', 'asc')-

$>$ get_where('v_order_detail', array('kategori_id' => \$kategori))->result();

\} else \{

$>$ result ()$; \quad\}$

\$data['listData'] = \$this->db->order_by('order_id', 'asc')->get('v_order_detail')-

// echo"<pre>";

// var_dump(\$data);die;

\$this->load->view('admin/report/printpenjualan_v', \$data); \} \}

$/{ }^{*}$ Location: ./application/controller/admin/Lap_penjualan.php */

\section{Admin Menu_makanan.php}

$<$ ?php

defined('BASEPATH') or exit('No direct script access allowed');

class Menu makanan extends MY Controller

\{ public function _ construct()

\{ parent::_construct();

\$this->cek_auth_admin();

\$this->load->library('template');

\$this->load->model('admin/menu_makanan_m');

\$this->resized_path = realpath (APPPATH . '../img/menu_folder');

\$this->thumbs_path = realpath(APPPATH . '../img/menu_folder/thumbs'); \} 
public function index()

\{ \$data['IistKategori'] = \$this->db->order_by('kategori_nama', 'asc')$>$ get('resto_kategori')->result();

\$this->template->display('admin/menu_makanan/view', \$data); \}

public function data_list()

$\{\quad$ L List $=$ \$this->menu_makanan_m->get_datatables () ;

$\$$ data $=$ array () ;

$\$$ no $=$ \$_POST['start'];

foreach (\$List as $\$ r)$ \{

$\$$ no++;

\$row = array () ;

\$menu_id = \$r->menu_id;

\$linkedit = site_url('admin/menu_makanan/editdata/' . \$menu_id);

\$row []$=$ \$no;

\$row[] = '<img src="' . base_url('img/menu_folder/thumbs/' . \$r->menu_foto . "'

width="150px" height="100px">');

\$row[] = \$r->menu_kode;

\$row []$=\$ r->$ menu_nama;

\$row $[$ = \$r->kategori_nama;

\$row [] = \$r->menu_waktu;

\$row []$=$ number_format $(\$ r->$ menu_harga, 0, ", ',');

\$row []$=$ number_format $(\$ r->$ menu_harga2, 0, ", ',');

\$row[] = ' <a href="' . \$linkedit . "' title="Edit Data">

$<$ i class="fa fa-edit" $></ i>$

$</$ a $>$

$<$ a onclick="hapusData(' . \$menu_id . ')" title="Hapus Data">

$<i$ class="fa fa-trash" $></ i>$ $<$ a $>$;

\$data[] = \$row;

\$output = array (

"draw" $\quad \Rightarrow$ \$ POST['draw'],

"recordsTotal" $=>$ \$this->menu_makanan_m->count_all(),

"recordsFiltered" => \$this->menu_makanan_m->count_filtered(),

);

"data" => \$data,

\}

echo json_encode(\$output);

public function adddata()

\{

\$data['listKategori'] = \$this->db->order_by('kategori_nama', 'asc')-

$>$ get('resto_kategori')->result();

\}

\$this->template->display('admin/menu_makanan/add', \$data);

private function nama_exists(\$nama)

\{

\$this->db->where('menu_nama', \$nama);

\$query = \$this->db->get('resto_menu');

if (\$query->num_rows ()$>0)\{$ return true;

\} else \{

return false;

\}

public function register_nama_exists()

\{

if (array_key_exists('nama', \$_POST)) \{ 


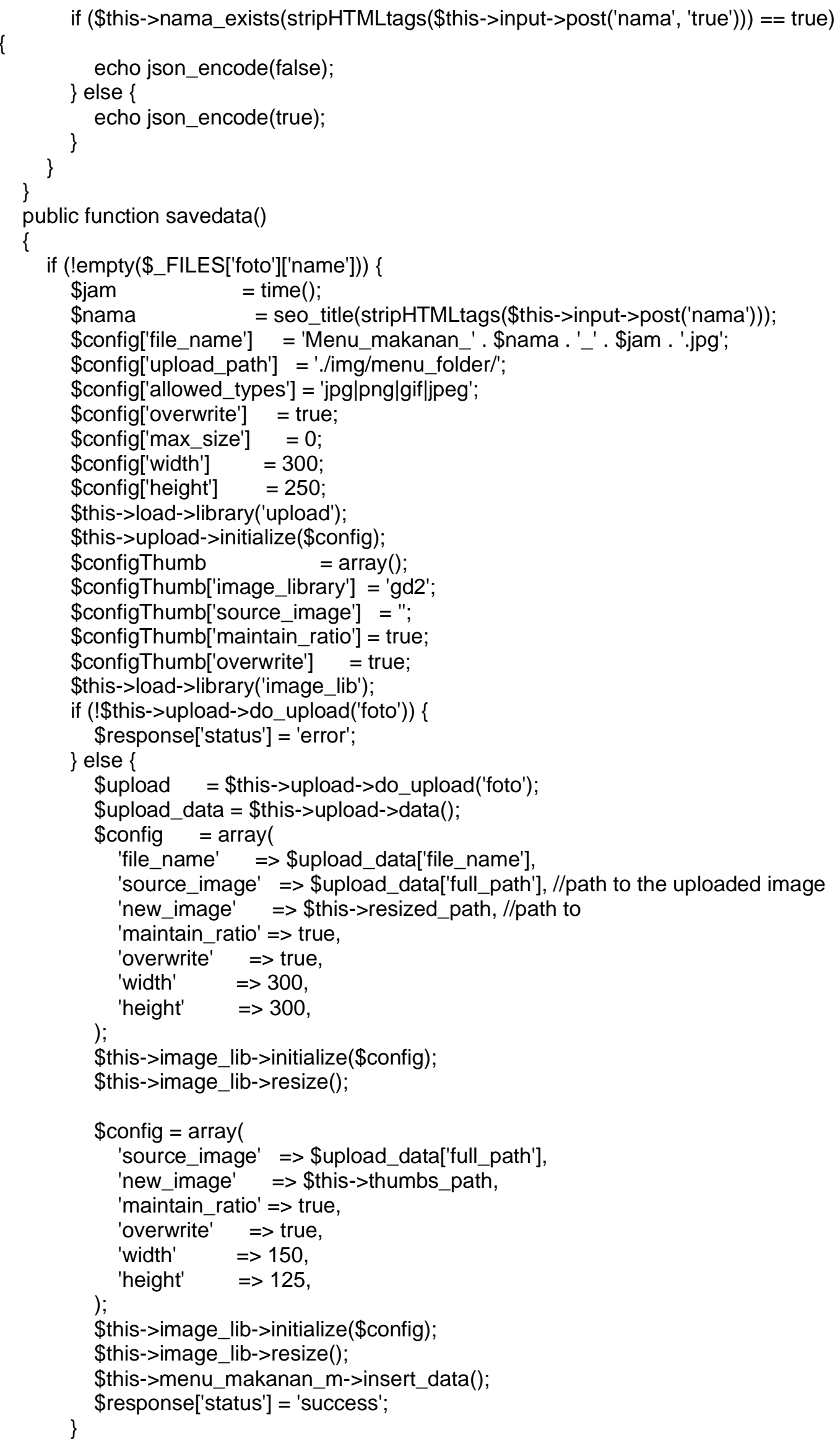




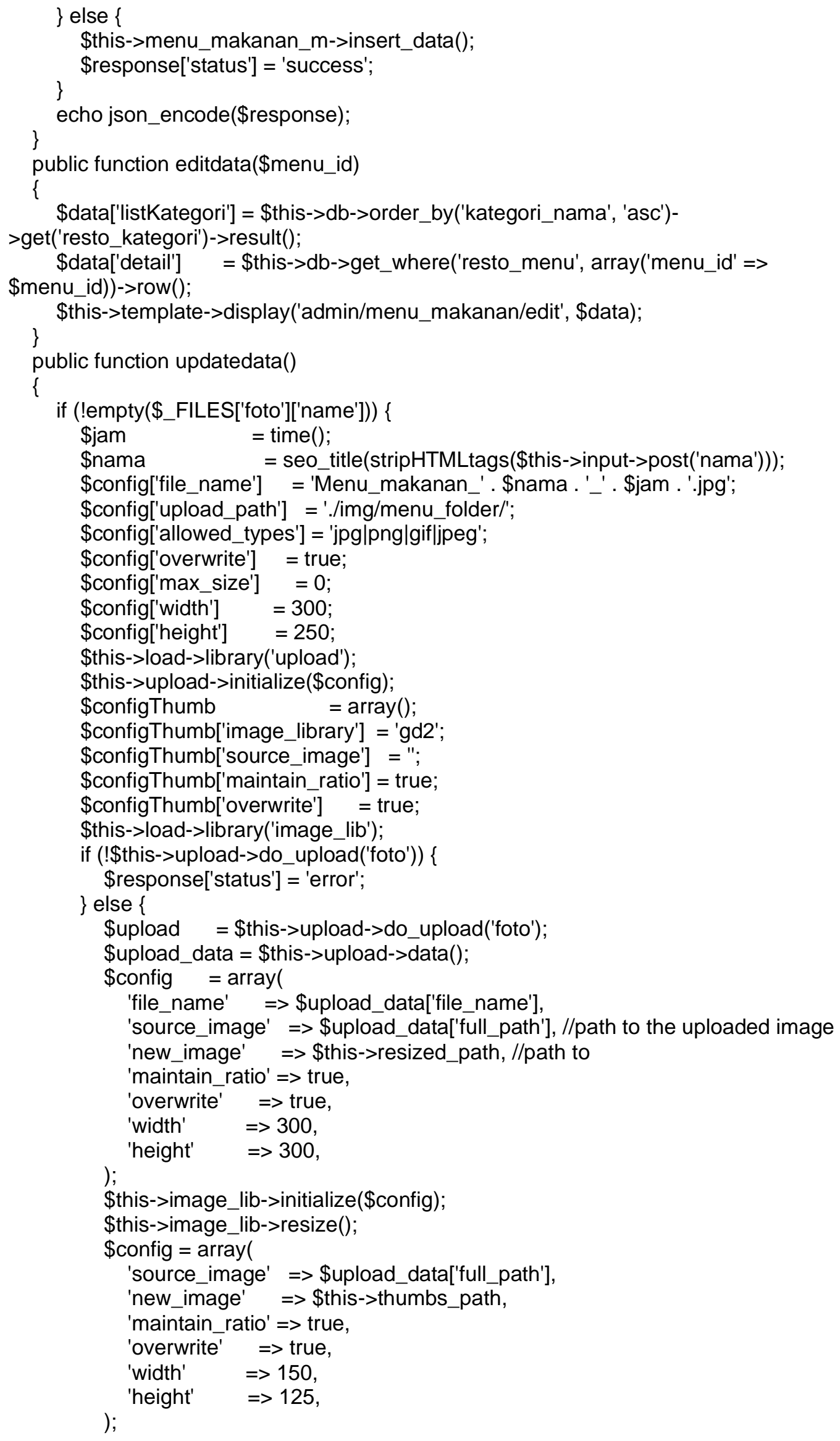




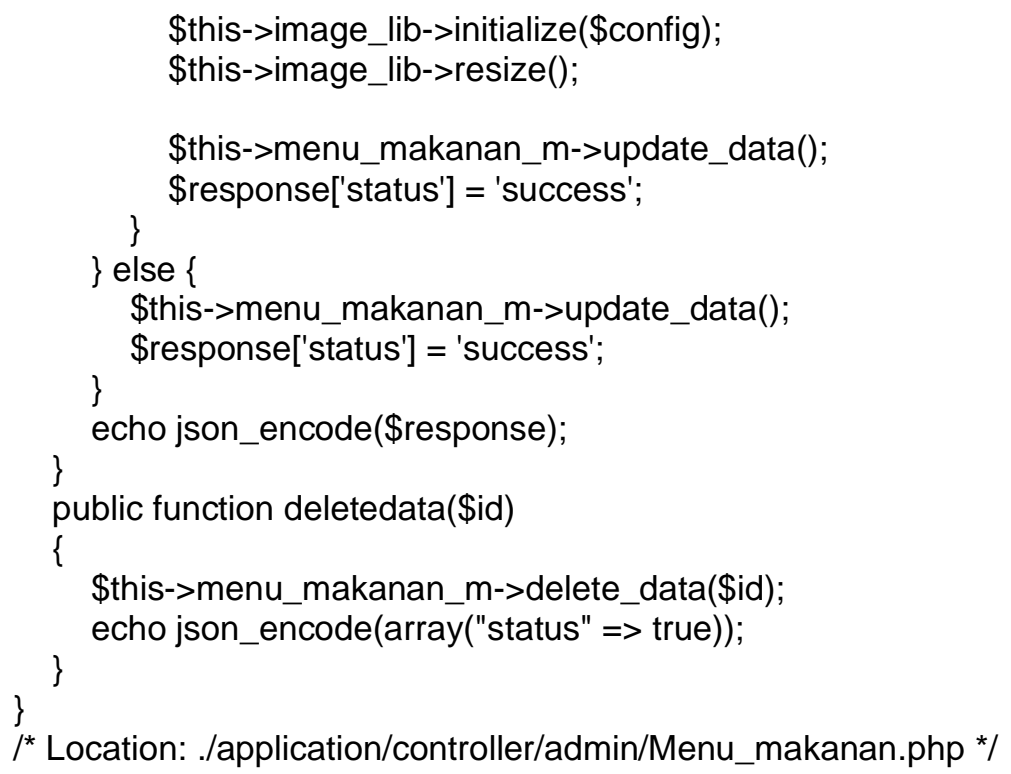

\section{Front Menuorder.php}

$<$ ?php

defined('BASEPATH') or exit('No direct script access allowed'); class Menuorder extends MY_Controller

\{

public function _ construct()

\{

parent::_construct();

\$this->load->library('template_front');

\}

\$this->load->model('front/menuorder_m');

public function index()

\{

\} /* Location: ./application/controller/front/Menuorder.php */

\subsection{Testing}

Pengujian Form Konfirmasi Pesanan: Dalam pengujian ini yang dilakukan yaitu dengan skenario pengujian : 1. Mengosongkan semua isian menu pesanan; 2. Mengosongkan nama pemesanan lalu mengklik konfirmasi order; 3 . Mengkosongkan no meja lalu mengklik knfirmasi order dan hasilnya pengujian sesuai harapan dengan kesimpulan Valid.

Tabel 1. Pengujian Blackbox Testing Form Konfirmasi Pesanan

\begin{tabular}{|c|c|c|c|c|c|}
\hline No & Skenario Pengujian & Test Case & Hasil yang diharapkan & $\begin{array}{c}\text { Hasil } \\
\text { Pengujian }\end{array}$ & Kesimpulan \\
\hline 1 & $\begin{array}{l}\text { Mengkosongkan semua } \\
\text { isian menu pesanan }\end{array}$ & $\begin{array}{l}\text { Menu: (Banana } \\
\text { Nugget 1) Menu: } \\
\text { (Kosong) }\end{array}$ & $\begin{array}{c}\text { Sistem akan menampilkan } \\
\text { notifikasi bahwa keranjang } \\
\text { order kosong }\end{array}$ & $\begin{array}{l}\text { Sesuai } \\
\text { Harapan }\end{array}$ & Valid \\
\hline 2 & $\begin{array}{l}\text { Mengkosongkan nama } \\
\text { pemesan lalu mengklik } \\
\text { "konfirmasi order" }\end{array}$ & $\begin{array}{l}\text { Nama: (Riri) } \\
\text { Nama: (Kosong) }\end{array}$ & $\begin{array}{l}\text { Sistem akan menolak dan } \\
\text { memberikan pesan peringatan } \\
\text { "Please Fill out this field" }\end{array}$ & $\begin{array}{l}\text { Sesuai } \\
\text { Harapan }\end{array}$ & Valid \\
\hline 3 & Mengkosongkan no meja & No Meja: (1) No & Sistem akan menolak dan & Sesuai & Valid \\
\hline
\end{tabular}




\begin{tabular}{|c|c|c|c|c|c|}
\hline No & Skenario Pengujian & Test Case & Hasil yang diharapkan & $\begin{array}{c}\text { Hasil } \\
\text { Pengujian }\end{array}$ & Kesimpulan \\
\hline & $\begin{array}{l}\text { lalu mengklik "konfirmasi } \\
\text { order" }\end{array}$ & Meja: (Kosong) & $\begin{array}{c}\text { memberikan pesan peringatan } \\
\text { "Please Select an item in the } \\
\text { list" }\end{array}$ & Harapan & \\
\hline
\end{tabular}

Sumber: Hasil penelitian (2020)

Pengujian Form Login Kasir: Dalam pengujian ini yang dilakukan yaitu dengan skenario pengujian : 1. Mengosongkan semua isian data login, lalu mengkilik "Login"; 2. Hanya mengisikan username dan password kosong, lalu mengkilik "Login"; 3. Username kosong dan password diisi, lalu mengkilik "Login"; 4. Mengisi dengan username salah dan password benar, lalu mengkilik "Login"; 5. Mengisi dengan username benar dan password salah, lalu mengkilik "Login"; 6. Mengisi dengan data yang benar, lalu mengklik "Login" dan hasilnya pengujian sesuai harapan dengan kesimpulan Valid.

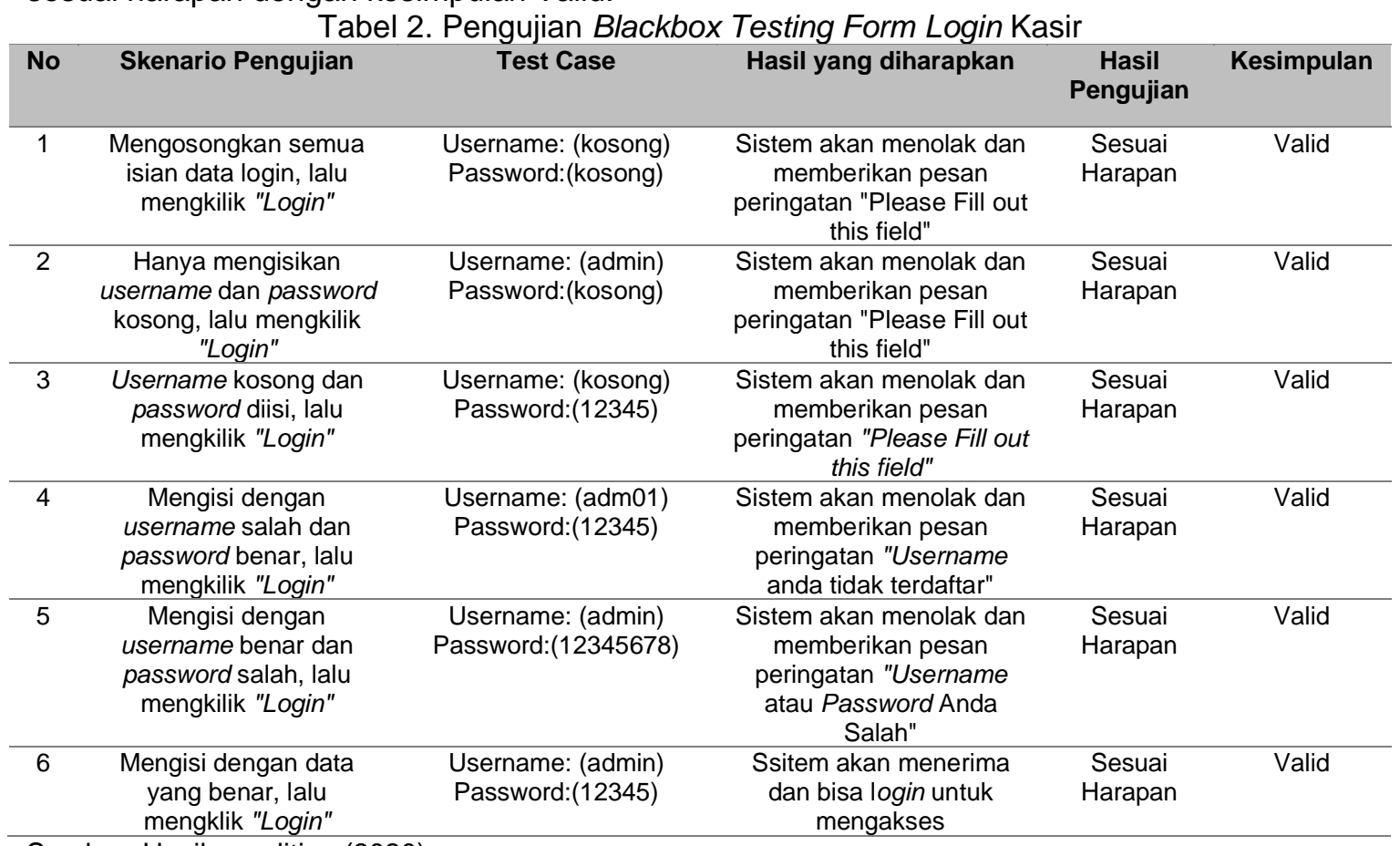

Sumber: Hasil penelitian (2020)

Pengujian Form Konfirmasi Pembayaran: Dalam pengujian ini yang dilakukan yaitu dengan skenario pengujian : 1. Mengosongkan detail bayar lalu klik "Bayar"; 2. Mengisi detail bayar dengan nominal kurang dari total bayar, lalu klik "Bayar"; 3. Mengisi detail bayar dengan nominal yang sesuai, lalu klik "Bayar" dan hasilnya pengujian sesuai harapan dengan kesimpulan Valid.

Tabel 3. Pengujian Blackbox Testing Form Konfirmasi Pembayaran

\begin{tabular}{cccccc} 
No & Skenario Pengujian & Test Case & Hasil yang diharapkan & $\begin{array}{c}\text { Hasil } \\
\text { Pengujian }\end{array}$ & Kesimpulan \\
\hline $\mathbf{1}$ & $\begin{array}{c}\text { Mengosongkan detail } \\
\text { bayar lalu klik "Bayar" }\end{array}$ & $\begin{array}{c}\text { Bayar:(50.000) } \\
\text { Bayar:(Kosong) }\end{array}$ & $\begin{array}{c}\text { Sistem akan menolak dan } \\
\text { memberikan pesan peringatan } \\
\text { "Bayar harus diisi" }\end{array}$ & $\begin{array}{c}\text { Sesuai } \\
\text { Harapan }\end{array}$ & Valid \\
\hline $\mathbf{2}$ & $\begin{array}{c}\text { Mengisi detail bayar } \\
\text { dengan nominal kurang } \\
\text { dari total bayar, lalu klik } \\
\text { "Bayar" }\end{array}$ & $\begin{array}{c}\text { Bayar:(50.000) } \\
\text { Bayar:(Kurang) }\end{array}$ & $\begin{array}{c}\text { Sistem akan menolak dan } \\
\text { memberikan pesan peringatan } \\
\text { "Bayar Kurang dari Total" }\end{array}$ & Sesuai & Valid \\
\hline $\mathbf{3}$ & $\begin{array}{c}\text { Mengisi detail bayar } \\
\text { dengan nominal yang } \\
\text { sesuai, lalu klik "Bayar" }\end{array}$ & Bayar:(50.000) & $\begin{array}{c}\text { Sistem menerima serta } \\
\text { menyimpannya didatabase lalu } \\
\text { meberikan notifikasi } \\
\text { "Pembayaran Selesai" dan struk } \\
\text { dapat diprint }\end{array}$ & Sesuai & Valid \\
\hline
\end{tabular}

Sumber: Hasil penelitian (2020) 


\subsection{Support}

Publikasi Web: Mengakses website dengan menggunakan aplikasi browser seperti Mozilla Firefox, Internet Explorer, Opera, Google Chrome dan yang lainnya.Yaitu dengan mengetikan alamat website ke dalam address bar pada aplikasi browser. Untuk domain names, mendaftarkan website Sistem Informasi pada yaitu salah satu web hosting yang telah banyak dipergunakan oleh pembuat web untuk publikasikan.

Spesifikasi Hardware \& Software: Adapun perangkat keras minimal yang diperlukan oleh kasir adalah sebagai berikut: Processor: Intel Core 2 Duo 2.27 Ghz; Memory Size (RAM): 2,00 GB (1,87 GB usable); Monitor : SVGA Colour 15"; Harddisk : 250 GB; Keyboard : 107 Keys; Mouse : Standard Mouse. Adapun perangkat lunak minimal yang digunakan untuk web server adalah sebagai berikut: Sistem Operasi: Windows 7; Bahasa Program: MySQL/Code Integer; Database Server: MySQL client version: mysqlnd; 5.0.11-dev - 20120503; Web Server: XAMPP Versi 3.2.2 (for windows); Database Tools : PhpMyAdmin versi 4.7.4; Framework CSS : Bootstrap.

\section{Kesimpulan}

Sistem informasi penjualan makanan dan minuman di Wejie Kopi berbasis web ini adalah sebuah sistem yang dapat digunakan untuk sebuah transaksi di Wejie Kopi. Dimana transaksi antara customer dan kasir jauh lebih efektif.

Kelebihan Sistem informasi penjualan makanan dan minuman di Wejie Kopi berbasis web ini yaitu mempermudah para customer melalukan pemesanan dengan hanya menggunakan tablet yang sudah disediakan di meja dan mengakses situs tersebut tanpa perlu melakukan pemesanan secara manual seperti sebelumnya. Kekurangan dari sistem informasi penjualan makanan dan minuman di Wejie Kopi berbasis web hanya bisa diakses oleh customer dan kasir tidak dengan bagian dapur.

\section{Referensi}

[1] Martono, "Pembuatan Aplikasi E-Menu (Electronic Menu) Berbasis Website Dan Android," J. IIm. Media Sisfo, vol. 12, no. 1, pp. 1036-1046, 2018.

[2] F. F. C. Deni Utama, Asahar Johar, "Aplikasi Pemesanan Makanan Dan Minuman Restaurant Berbasis Client Server Dengan Platform Android Dan Php Menggunakan Metode Centralized Dbms Architecture (Studi Kasus: Cafe Cempakoe Kota Bengkulu)," J. Rekursif, vol. 4, pp. 288-300, 2016.

[3] D. Defrina and D. P. Lestari, "Aplikasi Pemesanan Makanan Dan Minuman Online Aplication of Ordering Food and Beverages Online Based on Mobile Browser on Tiga Saudara Restaurant," J. IIm. Inform. dan Komput., vol. 22, no. 3, pp. 158-170, 2017.

[4] R. Febriyansyah, A. B. N. Negara, and N. Safriadi, "Rancang Bangun Aplikasi Pemesanan Menu Di Restoran Berbasis Web," J. Sist. dan Teknol. Inf., vol. 5, no. 3, pp. 1-5, 2017.

[5] G. W. Sasmito, "Penerapan Metode Waterfall Pada Desain Sistem Informasi Geografis Industri Kabupaten Tegal," J. Inform. J. Pengemb. IT, vol. 2, no. 1, pp. 6-12, 2017.

[6] M. Jannah and Sarwandi, Mahir Bahasa Pemrograman PHP. Jakarta: PT. Elex Media Komputindo, 2019.

[7] R. Yanto, Manajemen Basis Data Menggunakan MySQL. Yogyakarta: deepublish, 2015.

[8] B. Haqi, Aplikasi SPK Pemilian Dosen Terbaik Metode Simple Additive Weighting (SAW) Dengan Java. Yogyakarta: Deepublish Publisher, 2019.

[9] J. Enterprise, Membuat Website PHP dengan Codelgniter. Jakarta: Pt Elex Media Komputindo, 2015.

[10] S. Masripah, Nurhidayati, N. O. Syamsiah, and Haryani, Analisa Perancangan Sistem Informasi Akuntansi. Jakarta: Graha IImu, 2019.

[11] A. Lubis, Basis Data Dasar. Yogyakarta: deepublish, 2016.

[12] S. Janti, "Animasi Edukasi Interaktif Tes Kemampuan Konsentrasi Dengan Permainan Tebak Warna," J. Tek. Komput. AMIK BSI, vol. III, no. 1, pp. 106-113, 2017. 